\title{
Screening Employees for Undiagnosed Type 2 Diabetes Mellitus and Evaluation of Risk Scores in Tikur Anbessa Specialized Hospital, Addis Ababa, Ethiopia
}

\author{
Zenebe Negash Wakjira and Alemseged Beyene Berha* \\ Clinical Pharmacy Unit, Department of Pharmacology and Clinical pharmacy, School of Pharmacy, College of Health Science, Addis Ababa University, Addis Ababa, \\ Ethiopia \\ "Corresponding author: Alemseged Beyene Berha, Clinical Pharmacy Unit, Department of Pharmacology and Clinical pharmacy, School of Pharmacy, College of \\ Health Science, Addis Ababa University, Addis Ababa, Ethiopia, Tel: +251913258012; E-mail: alembeyene98@gmail.com
}

Received date: September 01, 2017; Accepted date: September 26, 2017; Published date: September 30, 2017

Copyright: @ 2017 Wakjira ZN, et al. This is an open-access article distributed under the terms of the Creative Commons Attribution License, which permits unrestricted use, distribution, and reproduction in any medium, provided the original author and source are credited.

\begin{abstract}
Background: Screening enables for identification of those individuals who are sufficiently high risk in the lag phase between the onset of latent hyperglycemia and clinical diagnosis which helps for early intervention. The objective of this study was to assess the employees' risk of developing undiagnosed type 2 diabetes mellitus and to determine their risk score in Tikur Anbessa Specialized Hospital (TASH).
\end{abstract}

Methods: A cross-sectional, quantitative method was conducted by using self-administered CANRISK score tool questionnaire. The stratified random sampling technique was used, and data collection took place from April 01 to June 01, 2015 for two months. The data were cleared, entered and analyzed using SPSS version 20.0. Binary Logistic regression was performed with statistical significance determined at $P<0.05$.

Results: Out of 1450 employees in TASH, 304 employees were recruited in this study. More than half, 167 $(54.9 \%)$ of the participants were females. Among study participant, $161(53 \%)$ were not involved in regular physical activity as well as $266(87.2 \%)$ participants did not feed healthy diet daily. Of a total $60(19.7 \%)$ had previous history of elevated blood pressure, $42(13.8 \%)$ of them had hypertension and/or $30(9.9) \%$ of them had taken drugs for hypertension. Among study participants screened via CANRISK scoring assessment tools $68.4 \%, 21.7 \%$ and $9.9 \%$ $(7.3 \%$ male and $2.6 \%$ female) were found to be in the categories of slightly elevated, moderate and high risk category of having pre-diabetes or diabetes, respectively.

Conclusion: It was found that $9.9 \%$ of the participant had a high risk score of having pre-diabetes or diabetes, which indicate the high occurrence of diabetes risk factors in those hospital employees who had been expecting a good awareness about the burden of the disease and its risk factors.

Keywords: Diabetes Mellitus; Undiagnosed type 2 diabetes; Risk factors; CANRISK score; Diabetes risk score

Abbreviations: ADA: American Diabetes Association; BMI: Body mass index $\left(\mathrm{kg} / \mathrm{m}^{2}\right)$; CANRISK: Canadian diabetes risk score; ETB: Ethiopian Birr; FINDRISC: Finnish Diabetes Risk Score; IDF: International Diabetes Federation; T2DM: Type 2 Diabetes Mellitus; WC: Waist circumference; WHO: World Health Organization

\section{Introduction}

Type 2 Diabetes mellitus (T2DM) is a metabolic disorder with multiple risk factors that characterized by a chronic increase in blood glucose level due to impairment in carbohydrate, fat, and protein metabolism that end with deterioration in insulin secretion and/or insulin action [1]. It is progressive lifelong conditions which cause ongoing destruction of cell that produces insulin and requires continuous medical management to reduce increase glucose level. The long term complication of hyperglycemia due to failure to control can cause damage, dysfunction and failure of organ such as heart, eye, kidney, nerve, blood vessel, etc. Type 2 diabetes, accounts over $90 \%$ of adults with diabetes, and mostly develops after middle age even though currently it goes down to younger age groups [2].

Globally the incidence of DM is increasing very rapidly following the increase in life expectance people concurrently with globalization and urbanization. In 2013 International Diabetes Federation (IDF) estimated that about 382 million people worldwide or $8.3 \%$ of adults were with diabetes and out of these about $80 \%$ live in low and middle income countries. If these trends continue, this number will increase to 500 million, by 2030 and by 2035 some 592 million people (1 adult in 10) will have diabetes. The largest increases will take place in the regions where developing economies are predominant. Many patients, up to $50 \%$ in most investigations, with type 2 diabetes are undiagnosed since they remain asymptomatic and therefore are undetected for many years [3].

The rise in prevalence is predicted to be much greater in developing than in developed countries (69\% versus $20 \%$ ) as well as becoming increasingly common among the younger age groups [3,4]. This increase in type 2 diabetes is inextricably linked to changes towards a Western lifestyle (high diet with reduced physical activity) in developing countries and the rise in prevalence of overweight and obesity. Given the increased risk and the rising health service burden 
of diabetes and its complications, it seems appropriate to advocate early detection in preparation for some type of educational or therapeutic intervention [5]. In the year 2013 greater than 20 million adults in Africa were estimated to have diabetes, which accounts about $4.8 \%$ of adults and this number could be rise to 41 million in the year 2035[6]. According to WHO estimates in Ethiopia about 800,000 cases were recorded in the year 2000, and this number will be expected to rise to 1.8 million by 2030 but in 2013 the report showed that 1.9 million Ethiopian people had diabetes [7].

Type 2 diabetes mellitus can be either from decrease in tissue sensitivity to insulin or impairment in insulin secretion or both because of many risk factors that include genetic and lifestyle related. These contributing factors can be either modifier (or preventable) such as increase in overweight and obesity, sedentary lifestyle, unhealthy diet, alcohol consumption, and tobacco smoking, physical inactivity, urbanization or non-modifier such as age, gender, family history of T2DM, genetic predisposition, history of gestational diabetes, and ethnicity etc. In addition the migration population from rural to urban also can contribute many things for modifiable risk factors $[8,9]$.

Lifestyle modifications can be a very effective way to prevent, delay the development and keep diabetes in control [10]. Even although there is a limited basis of belief that dietary change alone can provide a cure for type 2 diabetes, evidence has clearly shown that lifestyle variables are highly associated with risk of diabetes mellitus. Therefore, by adjusting these factors, it is possible to effectively reduce long term complications of the disease. This can be done with in cooperation with a multi-disciplinary team, especially health care personnel who can provide health related education regarding the risk factors related with diabetes; public health policies make plans to achieve the required outcome and increase awareness among community [11]. The US Cancer Prevention Study also provided evidence that stopping smoking for 10 years in men and five years in women could reduce the risk of diabetes to that of nonsmokers [12].

Most T2DM are initially asymptomatic for a long time and many people remain unaware of their illness until they have developed complication of disease as a result they diagnosed with at least one already developed a complication. Screening is an important approach for identifying subjects at high risk for developing diabetes easily and cost wise in lag phase between the onset of latent/asymptomatic stage and clinical investigation. It helps for prediction of risk score, which encourage early diagnose, identify people require further testing as well as prevention easily than medical measure and to set public health priorities[13]. Data from the United Kingdom Prospective Diabetes Study (UKPDS) came across this suggestion by demonstrating an indirect association between fasting plasma glucose at diagnosis, and adverse clinical outcomes [14].

One approach for detecting individuals at high risk for acquiring diabetes is the use of simple, practical, non-invasive and inexpensive risk score questionnaires. These risk score helps to predict risk without requiring medical or invasive measures, to quickly identify people who may be at a higher risk and who need to have their level of risk further investigated. CANRISK is one the tools that used for screening was adopted from a similar questionnaire that is being used in Finland as part of its national diabetes prevention program (FINDRISC) with the addition of a new question on ethnicity, education and gestational diabetes by the Public Health Agency of Canada (PHAC) that helps to identify risk of pre-diabetes or type 2 diabetes. It is intended for adult's aged 40 to 74 years, as well as younger individuals at increased risk of type 2 diabetes due to risk factors. After finishing the questionnaire provide an overall CANRISK score of the patient that shows risk of having pre-diabetes or diabetes $[15,16]$. Therefore, the present study aimed to assess the employees' risk of developing undiagnosed type 2 diabetes mellitus and to determine their risk score in Tikur Anbessa Specialized Hospital (TASH).

\section{Methodology}

\section{Study area and duration}

The study was conducted at Tikur Anbessa Specialized Hospital (TASH), which found in Lideta Subcity Addis Ababa, Ethiopia. TASH is one of the oldest and leading Teaching Hospitals having more than 430 beds with more than 1450 health professionals and administrative staffs. It has a multidisciplinary team of diverse professionals providing a wide range of healthcare services for approximately 300,000 patients each year. The employees form an extremely diverse community, representing almost every cultural and ethnic group found in Ethiopia. There is a wide spectrum of socioeconomic groups. The duration of the study was from April to June, 2015.

\section{Study design}

A cross-sectional, quantitative method was conducted on TASH employees by using a self-administered questionnaire and anthropometric measurement.

\section{Sample size determination}

Since there was no prior study in the study site an expected prevalence of $50 \%$ and desired precision of 0.05 and $95 \%$ confidence interval (CI) was used for the calculation. The sample size (n) required for the study was calculated using the formula to estimate a single population proportion.

$$
n=\frac{\left(z_{\alpha / 2}\right)^{2} P(1-P)}{d^{2}}
$$

Where, $\mathrm{n}=$ required sample size

$\mathrm{Z} \alpha / 2=$ critical value for normal distribution at $95 \%$ confidence interval $=1.96(\alpha=0.05), P=$ Proportion $=50 \%, d=$ margin of error $=$ $5 \%$

$$
\text { So, } n=\frac{(1.96)^{2}(0.5)(1-0.5)}{(0.05)^{2}}=384
$$

Nevertheless, by considering the resources, participant's response and the number of population (about 1450 employees) i.e. less than 10,000 the sample size was adjusted to:

$$
N f=\frac{384}{1+(384 / 1450)}=303.55 \approx 304
$$

\section{Statistical analysis}

The data was cleared, entered and statistical analysis was performed using SPSS software (Version 20.0). Stepwise descriptive analysis was carried out using risk score as dependent variable, with age, gender, smoking, physical activity, BMI, WC, ethnicity, educational status, religion, income, fruits and vegetables eating habit, previously measured history of blood pressure, presence of hypertension, gestational diabetes and high birth weight babies, family history of 
diabetes mellitus, and known hyperglycemia as independent variables. Binary logistic regression was used to assess the risk score toward T2DM with statistical significance determined at $\mathrm{P}<0.05$.

\section{Inclusion and exclusion criteria}

All voluntary individual employees who were above 18 years and had been working in TASH were enrolled in the present study. While, individuals with known DM or regularly taking drugs for hyperglycemia management and pregnant women who had been changed the anthropometric and laboratory parameters were excluded from study.

\section{Sampling procedure}

We used occupation based stratified random sampling among hospital employees in TASH. First the occupation was classified as professional and administrative employees and then into nine sub groups i.e. physicians (42), pharmacists and druggist (16), nurses (90), medical anesthesiologist and anesthesiology technicians (7), medical laboratory technologist and technicians (12), medical radiologic technologist and radiologists (5), midwiferies (4), physiotherapists (4) and administrative employees (124). Then sample was randomly selected from each professional and administrative employee that was proportional to the size of each strata and the number required was calculated based on the sample size requirement. All personnel in TASH, who were employees and working in TASH who fulfilled the criteria of inclusion had participated in the study.

\section{Data collection}

Data collections were performed using CANRISK evaluating tools; a questionaries' that consist an anthropometric measurement (weight, height, waist circumference) and self-report physical activity, educational status, religion, income, smoking, daily consumption of fruits \& vegetables, use of anti-hypertensive medication, history of high blood glucose, and family history of diabetes. The weight was measured by using electronic balance. A height measurement was done using a 'drop down' tape measure fixed at about 2 meters on a wall. Body mass index (BMI) is calculated by dividing weight by the square of height as; $\mathrm{BMI}=$ Weight $(\mathrm{kg}) /$ Height $(\mathrm{m})^{2}$. Waist circumference (WC) was measured by using non stretchy measuring tape at halfway between the lowest rib and the top of hip bone person stands with abdomen relaxed, arms at the sides, and feet together. Despite anthropometric measurement the other part of the questionnaire was filled by personal self-report of the participants.

Since there is no country specific scale for BMI and WC in our country to measure obesity, we use a WHO obesity cut point as standard during this study (BMI $\left(<18.5 \mathrm{~kg} / \mathrm{m}^{2}\right.$ : Under normal; 18.5-24.9 kg/m²: Normal; $25-29.9 \mathrm{~kg} / \mathrm{m}^{2}$ : Overweight; $30-39.9 \mathrm{~kg} / \mathrm{m}^{2}$ : Obese; $\geq 40 \mathrm{~kg} / \mathrm{m}^{2}$ : Morbidly obese) and WC (Men $<94 \mathrm{~cm}$ : normal; $\geq$ $94 \mathrm{~cm}$ : increased and Women $<80 \mathrm{~cm}$ : normal; $\geq 80 \mathrm{~cm}$ : increased).

The CANRISK has 12 types questions that include different variables that measure the outcome and then comparing the results with threshold scores for each of the 3 risk categories; low $<21$, moderate 21-32, high $>32$ and all were included in the analysis. The questionnaire was translated from English to Amharic national language to reduce language barriers and verbally explained to the participants who could not understand the medical jargon in the questionnaire.

\section{Ethical consideration}

Ethical clearance for the study was obtained from the of School of Pharmacy, College of Health Sciences, Addis Ababa University. An official support letter from the school of pharmacy was written to respective hospital administrative bodies and data collection was undertaken after permission was obtained from the administrative office. Study participants were asked for their consent before being asked for any information. The objective of the study was explained for every participant and was asked to give information only after they give their consent. No persons were obliged to participate in the study without his/her consent. The information provided by each respondent was kept confidential.

\section{Results}

Out of the total 1450 employees in TASH, 304 employees were recruited in this study. Of them, 167 (54.9\%) were female. The age range of the participants was 20 to 67 and majority (76\%) of them was under forty years. From the finding the participants BMI and WC were found between $14.0 \mathrm{~kg} / \mathrm{m}^{2}$ to $34.8 \mathrm{~kg} / \mathrm{m}^{2}$ and $56 \mathrm{~cm}$ to $110 \mathrm{~cm}$, respectively. Among these study participants 53 (17.4\%) were overweight, while 8 (2.6\%) grouped as obese and $83(27.3 \%)$ were in the range of elevated waist circumference. With regards to their physical activity more than half (53\%) were not involved in regular physical activity rather than the daily occasional activity and $87.2 \%$ participants did not have a habit of eating healthy diets (fruits and vegetable) regularly.

Of the total, $60(19.7 \%)$ had a personal history of high blood pressure, $42(13.8 \%)$ of them had hypertension and/or $30(9.9 \%)$ of them taken drugs for hypertension. Among the participant $57(18.8 \%)$ of them had at least a one-time elevation in blood sugar level and about 21 (13.9\%) of the female participants had reported to have gestational risen in blood glucose level. It was revealed that about 95 (31.3\%) of participant had a first and 27 (8.9\%) a second degree family history of diabetes mellitus. As the study was done in higher institution most $215(70.7 \%)$ participant had an education level of college or university and had income of greater than 5000 ETB. Most participants 179 (58.9\%) were the Orthodox religion follower. With respect to the smoking status of the participants, $13(4.3 \%)$ and $16(5.3 \%)$ had reported to be current and previous smokers, respectively. Of the sample participants screened via CANRISK scoring assessment tools 208 (68.4\%), 66 (21.7\%) and 30 (9.9\% (7.3\% male and 2.6\% female)) were found to be in the categories of slightly elevated, moderate and high risk category of having pre-diabetes or diabetes respectively.

The distribution of demographic data and risk factors versus CANRISK risk score were shown in Table 1 which state that the score increment along with rise in age, physical status such as BMI, WC, regular physical inactivity and lack of habit to eat vegetation as well as the existence of co-morbid condition such as blood pressure, family history of diabetes and high blood glucose level. There was also a decrease in risk score as the participants' income and educational status increase. 
Citation: Wakjira ZN, Berha AB (2017) Screening Employees for Undiagnosed Type 2 Diabetes Mellitus and Evaluation of Risk Scores in Tikur Anbessa Specialized Hospital, Addis Ababa, Ethiopia. J Diabetes Metab 8: 765. doi:10.4172/2155-6156.1000765

Page 4 of 10

\begin{tabular}{|c|c|c|c|c|c|}
\hline \multirow{2}{*}{\multicolumn{2}{|c|}{ Variable }} & \multicolumn{3}{|c|}{ CANRISK risk score range } & \multirow{3}{*}{$\begin{array}{l}\text { Total } \\
122(40.1 \%)\end{array}$} \\
\hline & & \multirow{2}{*}{$\begin{array}{l}\text { Low risk score } \mathbf{N}(\%) \\
103(33.9 \%)\end{array}$} & \multirow{2}{*}{$\begin{array}{l}\text { Moderate risk score N } \\
(\%)\end{array}$} & \multirow{2}{*}{$\begin{array}{l}\begin{array}{l}\text { High risk score } \mathbf{N} \\
(\%)\end{array} \\
3(1.0 \%)\end{array}$} & \\
\hline \multirow[b]{3}{*}{ Age (years) } & $20-29$ & & & & \\
\hline & $30-39$ & $77(25.3 \%)$ & $25(8.2 \%)$ & $7(2.3 \%)$ & $109(35.9 \%)$ \\
\hline & $>40$ & $28(9.2 \%)$ & $25(8.2 \%)$ & $20(6.6 \%)$ & $73(24.0 \%)$ \\
\hline \multirow[b]{2}{*}{ Gender } & Male & $84(27.6 \%)$ & $31(10.2 \%)$ & $22(7.3 \%)$ & 45.1 \\
\hline & Female & $124(40.8 \%)$ & $35(11.5 \%)$ & $8(2.6 \%)$ & $167(54.9 \%)$ \\
\hline \multirow[b]{4}{*}{$\mathrm{BMI}\left(\mathrm{kg} / \mathrm{m}^{2}\right.$} & <18.5(under normal) & $17(5.6 \%)$ & $2(0.7 \%)$ & $1(0.3 \%)$ & $20(6.6 \%)$ \\
\hline & 18.5-24.9(normal) & $166(54.6 \%)$ & $47(15.5 \%)$ & $10(3.3 \%)$ & $223(73.4 \%)$ \\
\hline & 25-29.9(over weight) & $24(7.9 \%)$ & $13(4.3 \%)$ & $16(5.3 \%)$ & $53(17.4 \%)$ \\
\hline & $>30$ (obese) & $1(0.3 \%)$ & $4(1.3 \%)$ & $3(1.0 \%)$ & $8(2.6 \%)$ \\
\hline \multirow{4}{*}{$\begin{array}{l}\text { Waist circumference } \\
\text { (WC) in cm }\end{array}$} & $<94$ (male) & $80(26.3 \%)$ & $26(8.6 \%)$ & $8(2.6 \%)$ & $114(37.5 \%)$ \\
\hline & $>=94($ male $)$ & $4(1.3 \%)$ & $5(1.6 \%)$ & $14(4.6 \%)$ & $23(7.6 \%)$ \\
\hline & $<80$ (female) & $87(28.6 \%)$ & $19(6.2 \%)$ & $1(0.3 \%)$ & $107(35.2 \%)$ \\
\hline & $>=80($ female $)$ & $37(12.2 \%)$ & $16(5.3 \%)$ & $7(2.3 \%)$ & $60(19.7 \%)$ \\
\hline \multirow[b]{4}{*}{ Ethnicity } & Oromo & $52(17.1 \%)$ & $18(5.9 \%)$ & $3(1.0 \%)$ & $73(24.0 \%)$ \\
\hline & Amhara & $95(31.2 \%)$ & $24(7.9 \%)$ & $18(5.9 \%)$ & $137(45.1 \%)$ \\
\hline & Tigre & $25(8.2 \%)$ & $10(3.3 \%)$ & $2(0.7 \%)$ & $37(12.2 \%)$ \\
\hline & Other & $36(11.8 \%)$ & $14(4.6 \%)$ & $7(2.3 \%)$ & $57(18.8 \%)$ \\
\hline \multirow[b]{4}{*}{ Educational status } & Some high school or less & $12(3.9 \%)$ & $9(3.0 \%)$ & $12(3.9 \%)$ & $33(10.9 \%)$ \\
\hline & High school diploma & $22(7.2 \%)$ & $2(0.7 \%)$ & $3(1.0 \%)$ & $27(8.9 \%)$ \\
\hline & Some college or university & $25(8.2 \%)$ & $4(1.3 \%)$ & 0 & $29(9.5 \%)$ \\
\hline & University/college degree & $149(49.0 \%)$ & $51(16.8 \%)$ & $15(4.9 \%)$ & $215(70.7 \%)$ \\
\hline \multirow[b]{5}{*}{ Religion } & Orthodox & $126(41.4 \%)$ & $30(9.9 \%)$ & $23(7.6 \%)$ & $179(58.9 \%)$ \\
\hline & Muslim & $30(9.9 \%)$ & $11(3.6 \%)$ & 0 & $41(13.5 \%)$ \\
\hline & Protestant & $34(11.2 \%)$ & $10(3.3 \%)$ & $3(1.0 \%)$ & $47(15.5 \%)$ \\
\hline & Catholic & $11(3.6 \%)$ & $8(2.6 \%)$ & $4(1.3 \%)$ & $23(7.6 \%)$ \\
\hline & Others & $7(2.3 \%)$ & $7(2.3 \%)$ & 0 & $14(4.6 \%)$ \\
\hline \multirow{6}{*}{$\begin{array}{l}\text { Income status (ETB per } \\
\text { month) }\end{array}$} & $<1000$ & $8(2.6 \%)$ & $1(0.3 \%)$ & $2(0.7 \%)$ & $11(3.6 \%)$ \\
\hline & $1000-1500$ & $9(3.0 \%)$ & $1(0.3 \%)$ & $1(0.3 \%)$ & $11(3.6 \%)$ \\
\hline & $1500-2000$ & $13(4.3 \%)$ & $7(2.3 \%)$ & $7(2.3 \%)$ & $27(8.9 \%)$ \\
\hline & $2000-3000$ & $35(11.5 \%)$ & $6(2.0 \%)$ & $3(1.0 \%)$ & $44(14.5 \%)$ \\
\hline & $3000-5000$ & $57(18.8 \%)$ & $6(2.0 \%)$ & $3(1.0 \%)$ & $66(21.7 \%)$ \\
\hline & $>5000$ & $86(28.3 \%)$ & $45(14.8 \%)$ & $14(4.6 \%)$ & $145(47.7 \%)$ \\
\hline Physical activity & Yes & 101(33.2\%) & $32(10.5 \%)$ & $10(3.3 \%)$ & $143(47.0 \%)$ \\
\hline
\end{tabular}


Citation: Wakjira ZN, Berha AB (2017) Screening Employees for Undiagnosed Type 2 Diabetes Mellitus and Evaluation of Risk Scores in Tikur Anbessa Specialized Hospital, Addis Ababa, Ethiopia. J Diabetes Metab 8: 765. doi:10.4172/2155-6156.1000765

Page 5 of 10

\begin{tabular}{|c|c|c|c|c|c|}
\hline & No & $107(35.2 \%)$ & $34(11.2 \%)$ & $20(6.6 \%)$ & $161(53.0 \%)$ \\
\hline \multirow{4}{*}{$\begin{array}{l}\text { Vegetable or fruit eat per } \\
\text { weeks }\end{array}$} & Every day & $31(10.2 \%)$ & $6(2.0 \%)$ & $1(0.3 \%)$ & $38(12.5 \%)$ \\
\hline & 2-3day & $90(29.6 \%)$ & $33(10.9 \%)$ & $8(2.6 \%)$ & $131(43.1 \%)$ \\
\hline & Once & $83(27.3 \%)$ & $21(6.9 \%)$ & $13(4.3 \%)$ & $117(38.5 \%)$ \\
\hline & Not at all & $4(1.3 \%)$ & $6(2.0 \%)$ & $8(2.6 \%)$ & $18(5.9 \%)$ \\
\hline \multirow{3}{*}{$\begin{array}{l}\text { History of blood } \\
\text { Pressure increase }\end{array}$} & Yes & $28(9.2 \%)$ & $12(3.9 \%)$ & $20(6.6 \%)$ & $60(19.7 \%)$ \\
\hline & No & $158(52.0 \%)$ & $42(13.8 \%)$ & $4(1.3 \%)$ & $204(67.1 \%)$ \\
\hline & Don't known & $22(7.2 \%)$ & $12(3.9 \%)$ & $6(2.0 \%)$ & $40(13.2 \%)$ \\
\hline \multirow[b]{2}{*}{ Hypertension (HTN) } & Yes & $20(6.6 \%)$ & $8(2.6 \%)$ & $14(4.6 \%)$ & $42(13.8 \%)$ \\
\hline & No & $188(61.8 \%)$ & $58(19.1 \%)$ & $16(5.3 \%)$ & $262(86.2 \%)$ \\
\hline \multirow[b]{2}{*}{ HTN medication } & Yes & $13(4.3 \%)$ & $6(2.0 \%)$ & $11(3.6 \%)$ & $30(9.9 \%)$ \\
\hline & No & $195(64.1 \%)$ & $60(19.7 \%)$ & $19(6.2 \%)$ & $274(90.1 \%)$ \\
\hline \multirow{3}{*}{$\begin{array}{l}\text { History of blood glucose } \\
\text { increase }\end{array}$} & Yes & $6(2.0 \%)$ & $31(10.2 \%)$ & $20(6.6 \%)$ & $57(18.8 \%)$ \\
\hline & No & $169(55.6 \%)$ & $26(8.6 \%)$ & $4(1.3 \%)$ & $199(65.5 \%)$ \\
\hline & Don't know & $33(10.9 \%)$ & $9(3.0 \%)$ & $6(2.0 \%)$ & $48(15.8 \%)$ \\
\hline \multirow[b]{2}{*}{ Gestational diabetes } & Yes & $3(2.0 \%)$ & $15(9.9 \%)$ & $3(2.0 \%)$ & $21(13.9 \%)$ \\
\hline & No & $108(71.5 \%)$ & $18(11.9 \%)$ & $4(2.6 \%)$ & $130(86.1 \%)$ \\
\hline \multirow{3}{*}{$\begin{array}{l}\text { Birth baby greater than } 4 \\
\mathrm{~kg}\end{array}$} & Yes & $10(6.6 \%)$ & $8(5.3 \%)$ & $2(1.3 \%)$ & $20(13.2 \%)$ \\
\hline & No & $99(65.6 \%)$ & $24(15.9 \%)$ & $5(3.3 \%)$ & $128(84.8 \%)$ \\
\hline & Don't know or not applicable & $2(1.3 \%)$ & $1(0.7 \%)$ & 0 & $3(2.0 \%)$ \\
\hline \multirow[b]{3}{*}{ Smoking status } & Non-smoker & $196(64.5 \%)$ & $56(18.4 \%)$ & $23(7.6 \%)$ & $275(90.5 \%)$ \\
\hline & Current smoker & $7(2.3 \%)$ & $3(1.0 \%)$ & $3(1.0 \%)$ & $13(4.3 \%)$ \\
\hline & Previous smoker & $5(1.6 \%)$ & $7(2.3 \%)$ & $4(1.3 \%)$ & $16(5.3 \%)$ \\
\hline \multirow[b]{7}{*}{ Family history of DM } & Mother & $20(6.6 \%)$ & $10(3.3 \%)$ & $3(1.0 \%)$ & $33(10.9 \%)$ \\
\hline & Father & $18(5.9 \%)$ & $8(2.6 \%)$ & $7(2.3 \%)$ & $33(10.9 \%)$ \\
\hline & Brother or sister & $12(3.9 \%)$ & $3(1.0 \%)$ & $3(1.0 \%)$ & $18(5.9 \%)$ \\
\hline & Children & $5(1.6 \%)$ & $1(0.3 \%)$ & 0 & $6(2.0 \%)$ \\
\hline & Other & $16(5.3 \%)$ & $10(3.3 \%)$ & $1(0.3 \%)$ & $27(8.9 \%)$ \\
\hline & No /don't know & $134(44.1 \%)$ & $32(10.5 \%)$ & $16(5.3 \%)$ & $182(59.9 \%)$ \\
\hline & Mother-father & $3(1.0 \%)$ & $2(0.7 \%)$ & 0 & $5(1.6 \%)$ \\
\hline \multicolumn{6}{|c|}{$\begin{array}{l}\text { +South Nation and Nationality, Somali, Benshagul Gumize, Gambela, Afar, Harargie } \\
\text { ++Joba, Wakefecha, Mesereta-Kiristose } \\
\text { +++Grandfather, Grandmother, Uncle, Aunt, Cousin, etc. }\end{array}$} \\
\hline
\end{tabular}

Table 1: Distribution of demographical and risk factors by CANRISK Score range of participants at Tikur Anbessa Specialized Hospital (TASH), Addis Ababa Ethiopia, April- June, 2015 ( $\mathrm{N}=304)$.

Of the 16 risk factors investigated age $(\mathrm{p}=0.000)$, gender $(\mathrm{p}=0.002)$, BMI for overweight and obese $(\mathrm{p} \leq 0.001)$, WC $(\mathrm{p}=0.000)$, educational status for high school and less $(\mathrm{p}=0.000)$, history of increase blood $\mathrm{BP}$ $(\mathrm{p}=0.000), \operatorname{HTN}(\mathrm{p}=0.000)$, history of increase blood $\operatorname{sugar}(\mathrm{p}=0.000)$, gestational DM $(\mathrm{p}=0.039)$ and smoking status $(\mathrm{p}=0.036)$ were statistically significant $(\mathrm{p}<0.05)$ independent risk factor for undiagnosed type 2 diabetes. The results of logistic regression model are shown in Table 2. 
Citation: Wakjira ZN, Berha AB (2017) Screening Employees for Undiagnosed Type 2 Diabetes Mellitus and Evaluation of Risk Scores in Tikur Anbessa Specialized Hospital, Addis Ababa, Ethiopia. J Diabetes Metab 8: 765. doi:10.4172/2155-6156.1000765

\begin{tabular}{|c|c|c|c|}
\hline Variable & P-value & Odds ratios (ORs) & 95\% confidence intervals (C.I.) \\
\hline \multicolumn{4}{|l|}{ Age } \\
\hline $20-29$ & Ref. & & \\
\hline 30-39 & 0 & 0.067 & $0.019,0.235$ \\
\hline$>40$ & 0 & 0.182 & $0.072,0.457$ \\
\hline \multicolumn{4}{|l|}{ Gender } \\
\hline Female $(F)$ & Ref. & & \\
\hline Male (M) & 0.002 & 3.802 & $1.635,8.843$ \\
\hline \multicolumn{4}{|l|}{ BMI } \\
\hline Normal (BMI 18.5-24.9 kg/m²) & Ref. & & \\
\hline Under normal $\left(\mathrm{BMI}<18.5 \mathrm{~kg} / \mathrm{m}^{2}\right)$ & 0.915 & 1.121 & $0.136,9.233$ \\
\hline Over weight (BMI 25-29.9 kg/m²) & 0 & 9.211 & $3.883,21.849$ \\
\hline Obese $\left(\mathrm{BMI}=/>30 \mathrm{~kg} / \mathrm{m}^{2}\right)$ & 0.001 & 12.78 & $2.671,61.156$ \\
\hline \multicolumn{4}{|l|}{ Waist circumference (WC) } \\
\hline Normal (M: WC $<94 \mathrm{~cm}$ and F: $\mathrm{WC}<80 \mathrm{Cm}$ ) & Ref. & & \\
\hline Increase $(\mathrm{M}: \mathrm{WC}=/>94 \mathrm{~cm}$ and $\mathrm{F}: \mathrm{WC}=1>80 \mathrm{Cm})$ & 0 & 0.039 & $0.015,0.103$ \\
\hline \multicolumn{4}{|l|}{ Educational status } \\
\hline Some University or college degree and above & Ref. & & \\
\hline High school or less & 0 & 8.724 & $3.615,21.050$ \\
\hline Diploma & 0.333 & 1.908 & $0.515,7.065$ \\
\hline \multicolumn{4}{|l|}{ Income status (ETB) } \\
\hline$>5000$ & Ref. & & \\
\hline$<1000$ & 0.378 & 2.079 & $0.408,10.595$ \\
\hline $1000-1500$ & 0.951 & 0.936 & $0.111,7.860$ \\
\hline $2000-3000$ & 0.023 & 3.275 & $1.179,9.101$ \\
\hline $1500-2000$ & 0.567 & 0.685 & $0.187,2.501$ \\
\hline $3000-5000$ & 0.217 & 0.446 & $0.124,1.607$ \\
\hline \multicolumn{4}{|l|}{ Physical activity } \\
\hline Yes & Ref. & & \\
\hline No & 0.118 & 0.53 & $0.239,1.174$ \\
\hline \multicolumn{4}{|l|}{ Vegetable or fruit eat } \\
\hline Every day & Ref. & & \\
\hline Not every day & 0.144 & 0.221 & $0.029,1.671$ \\
\hline \multicolumn{4}{|l|}{ History of increase blood BP } \\
\hline No & Ref. & & \\
\hline Yes & 0 & 11.7 & $5.102,26.828$ \\
\hline
\end{tabular}


Citation: Wakjira ZN, Berha AB (2017) Screening Employees for Undiagnosed Type 2 Diabetes Mellitus and Evaluation of Risk Scores in Tikur Anbessa Specialized Hospital, Addis Ababa, Ethiopia. J Diabetes Metab 8: 765. doi:10.4172/2155-6156.1000765

Page 7 of 10

\begin{tabular}{|c|c|c|c|}
\hline \multicolumn{4}{|l|}{ HTN } \\
\hline No & Ref. & & \\
\hline Yes & 0 & 7.687 & $3.396,17.400$ \\
\hline \multicolumn{4}{|c|}{ History of increase blood sugar } \\
\hline No & Ref. & & \\
\hline Yes & 0 & 12.811 & $5.562,29.509$ \\
\hline \multicolumn{4}{|l|}{ Gestational DM } \\
\hline No & Ref. & & \\
\hline Yes & 0.039 & 5.25 & $1.085,25.395$ \\
\hline \multicolumn{4}{|l|}{ High Baby Birth } \\
\hline No & Ref. & & \\
\hline Yes & 0.239 & 2.8 & $0.505,15.521$ \\
\hline \multicolumn{4}{|l|}{ Smoking status } \\
\hline Non-smoker & Ref. & & \\
\hline Current smokers & 0.036 & 0.274 & $0.082, .918$ \\
\hline Previous smoker & 0.904 & 0.9 & $0.162,5.007$ \\
\hline \multicolumn{4}{|l|}{ Family history of DM } \\
\hline No & Ref. & & \\
\hline First degree relative & 0.21 & 1.645 & $0.755,3.582$ \\
\hline Second degree relative & 0.383 & 0.399 & $0.051,3.138$ \\
\hline
\end{tabular}

Table 2: Logistic regression of bivariate analysis of selected independent Variables in undiagnosed DM participants at Tikur Anbessa Specialized Hospital (TASH), Addis Ababa Ethiopia, April-June, 2015 (N=304).

\section{Discussion}

Screening is one of the most important methods for early identification of an asymptomatic type 2 diabetes mellitus which is one of health concerns in the current world. The result of this simple way of screening using CANRISK risk score assessment tool in study area TASH, tries to identify the most important risk factors which is the indicators of asymptomatic DM easy and cost wise. The risk score increase in line with the occurrence of determinant risk factors that were associated with DM.

In this study $30(9.9 \%)$ of participants had of the high risk score. Nearly three forth $231(76 \%)$ of participates were found in the age below 40 years with $10(3.3 \%)$ high risk score. The risk score increased from $1 \%$ in the $20-29$ years age groups to about $6.6 \%$ in the above 40 years. This finding was in agreement with prior studies by Otero et al., 2011 who reported an increase in risk from $0.5 \%$ in the $12-34$ years age groups to about $10-14 \%$ in the 75 years and above [17]. Our study result of T2DM risk factors of odds ratio (ORs) 0.182 finding was lower compared to the previous works that had been reported by Acemoglu et al. who found OR of 3.99, 4.3 and 6.16 for the age rang 40-49 year, 50-59 years and those above 60 years, respectively [18]. The OR of our result is less than one that might be due to age distributions in the younger groups and small number of participants above 40 years. The other study conducted in Kuwait by Al Khalaf et al. 2007 strengthen that age was first significant independent predictor [OR 3.72(1.05-13.2)] [19]. Responsible mechanisms of age-related risk increase include decreased insulin sensitivity and decreased $\beta$-cell function [20]. However, significant number of the younger individuals (3.3\%) who participated in this study showed high risk score for developing DM.

Our study participant's CANRISK tool obesity assessment which can obtained from body mass index (BMI) and waist circumferences (WC) variables which is the indicator of the degree of obesity result showed that, $17.4 \%$ were recorded to be overweight, $2.6 \%$ were obese and about $27.3 \%$ had elevated WC. In line with this study, a study conducted by On'Kin et al. 2008 in Congo reported that both total obesity and abdominal obesity were positively associated with all cases of DM (32\% in total obesity vs. $18.9 \%$ in non-obese; $\mathrm{P}<0.0001$ and $90.4 \%$ in abdominal obese vs. $18.1 \%$ in non-obese; $\mathrm{P}<0.0001$ ) [21]. The study conducted in India by Ahmad et.al, 2011 also showed that index of obesity (BMI, $>25 \mathrm{~kg} / \mathrm{m}^{2}$ and increased WC) at least double occurrence risk of DM [22]. In addition study by Azimi-Nezhad et al., 2008 in Iran WC is significant associated with DM, ORs of $1.031(1.012-1.052)$ with $\mathrm{p}<0.001$ [23]. In this study OR for overweight 9.211 (3.883-21.849), $\mathrm{P}=0.000$ and obese 12.78(2.671-61.156) $\mathrm{P}=0.001$ which is statistically significant and in line with previous study while 
increased WC $0.39(0.015-0.103), \quad \mathrm{P}<0.001$ which is statistically significant but in contrast protective, which may be due to small sample or lack of standard ethnic specific classification of WC.

The finding of the present study has shown that physical activity has no significant association with the development of DM (p-value $>0.05$ ). This insignificance may be due to small sample size. Similarly, the study conducted in Bishoftu Town, in Ethiopia also reported an insignificant association between physical activity and undiagnosed DM with OR 1.86 (0.73- 4.77) [20]. A study conducted in Kerala, India by Omolafe et al. 2010 showed that physical activity is a protective factor for the development of DM with OR 0.11(0.05-0.19) $\mathrm{p}<0.01$ [24]. In contrast to our finding, reports from the study conducted in Nyenwe, Nigeria showed that an OR of 2.9 (2.0-4.1) with P-value $<0.001$ [25]. In addition, a study conducted in Uganda by Mutebi et al. result indicates a significant relation between physical activity and DM (OR 3.723 (1.709-8.111)), $\mathrm{P}<0.001$ [26].

With respect to the blood pressure status about $42(13.8 \%)$ of the participants had hypertension which is a strong determinant risk factor for T2DM simultaneously with a history of high BP and the risk of occurrence DM 7.619 fold in this study relative to those of normal BP with p-value 0.000. Similarly, Acemoglu et al., who studied the risk factors of T2DM in Turkey, showed that hypertension enhance the risk of diabetes and recorded a 2.05-fold risk [18]. According to the Health Survey, $51 \%$ of diabetics had hypertension and a 2.5 -fold risk of diabetes in hypertension, less than that noticed from the present study. According to a recent JNC VII report, hypertension is twice as common among diabetics [27].In addition, Govindarajan et al., 2006 undergone large prospective cohort study that involve 12,550 adults and almost 2.5 times more likely in persons with hypertension than those of normal BP for developing DM [28]. Study of Al Khalaf et al., 2007 in Kuwait showed use of blood pressure medication (OR 2.66, 95\% CI: 1.00-7.05) were significant predictors [19].

Although the study result show that about 95 (31.3\%) and 27 (8.9\%) study participants reported the presence of first and second degree relative family history of DM, respectively, and it was found to be insignificant to predict the risk of developing DM (OR 1.6645(0.755, 3.582) with p-value 0.210$)$ ). This finding is inconsistent with the study conducted in Thailand by Aekplakorn et al., 2006 who reported history of diabetes in parent or sibling to have 2.95(2.22-3.92), times increased risk with p-value 0.88 [29]. In contrast, of this, reports from Mutebi et al. in Uganda (OR 2.852 (1.289-6.310), P-value 0.008) [26] also showed significant association between family history of DM and DM risk. The study conducted in India by Ahmad et.al, 2011 also showed that family history increase risk of developing DM 2-3 times [22]. Dong et al. 2011 study indicates family history of DM ORs of 5.41 (3.48-8.40) with p of 0.0017 shown to be a critical indicator for increased risk of diabetes [30]. The probable reason for the statistical insignificance of these risk factors in the present study might be a low sample size or low diagnosed DM especially T2DM because it is asymptomatic for a long period of time and they are also lacking of awareness in most population of our country.

In this study, about $21(13.9 \%)$ of the female participants had gestational DM and $18(11.9 \%)$ of these were at moderate to high risk score with ORs $5.25(1.085,25.395), \mathrm{p}<0.04$ i.e. about 5times risk for developing T2DM. This finding is in agreement with the study that had been done by Rhode Island, USA by Verma et al., 2002, that about $27.2 \%$ women to be with GDM and $8.2 \%$ control women acquire insulin resistant syndrome (IRS) by 11 years after delivery (ORs 5.6(2.6-12.3)) [31]. Dong et al. 2011 study also showed that a history of hyperglycemia (ever been told have hyperglycemia or latent diabetes, including gestational diabetes) significantly (ORs 16.52 (9.00-30.30) with p-value of 0.00 mark risk factors of DM [30]. In contrast to this, study of Zaafir et al. 2010 showed that history of gestational diabetes were insignificant risk factors [13].

The educational status of the present study participant of the sample were more likely of educated part of the Ethiopian context, with $215(70.7 \%)$ of whom attended college/university degree education and $15(4.9 \%)$ high risk score, which is inconsistent with the report of Otero et al. 2010 showing $68.2 \%$ acknowledging college/university degree education had a risk score of $6.8 \%$ of developing type 2 DM [17]. Most of the presents study participants were health professional being a study was conducted on hospital employees. So they had good awareness about the risk factors and about the disease state. In this study those with lower education level had about nine times (8.724) opportunity to develop diabetes in comparison with higher education level. About half of the participants 145(47.7\%) have a monthly income of greater than 5000 ET birr that might help themto keep affecting economic situation which was an important factor hindering the adoption of healthy lifestyles.

Even though smoking is one the most risk factor for many diseases currently, in this study it was not associated with the risk of developing DM. Conversely, a study conducted in Japanese by Kawakami et al., 1997, had shown that smoking contribute about 3.27 times higher risk for development of T2DM in those who use 16-26 cigarette per day when equated to non-smokers [32] and a study by Hur et al. 2007, in Korea, which was done over 8-years period also indicate that, the risk of having diabetes was 1.6 (95\% CI, 1.29-1.97) for those keeping smoke compared with 1.22 (95\% CI,0.96-1.55) for those stop [33]. In addition to this study of Zaafir et al., 2010 showed that smoking $\geq 5$ years ORs 3.18 (1.64-6.19) were a significant risk factor [13]. The lack of association in the present study could be justified by a small participant of smokers in the study or may lack openness of participants to fulfill the question.

Even though the gender difference in the prevalence for risk factors is relatively low, there is an increase in risk factors such as obesity in male and this was observed in our study that male to be more to have undiagnosed DM (ORs $3.8(1.635,8.843)$ with p-value 0.002$)$. The male noticeability in having of undiagnosed DM were similar to the result exposed by the studies done by On'Kin et al., 2008 in Congo who reported that the OR for DM was 1.44 comparing males with females [21] and Otero et al. 2006 in Canada who reported OR of 1.22 (1.12-1.33) with p-value 0.00) [17]. In contrary to our result, a study conducted in Kuwait by Al Khalaf et al., 2007 show that sex were insignificant independent predictor (ORs) 1.04 (0.45-2.40) with pvalue $0.93[19]$.

\section{Conclusion}

In the present study, it was observed that $9.9 \%$ of undiagnosed TASH employees were in high risk for developing T2DM according to the CANRISK risk score tools. There were also observed that increased risk of undiagnosed DM existed in all age groups indicating exposure of the population at mass. The factors related with increased risk of undiagnosed DM were potentially modifiable. Therefore, targeting the prevention to such a modifiable risk factors might reduce the prevalence of risk of undiagnosed DM and screening of DM in such individuals particularly those having high WC and history of 
hypertension brings more those who lacks awareness for medical attention.

As it was seen from the result the high education level health professionals has less risk (6.98\%) for developing DM compared to some high school or less (36.36\%). If this study is take place in most other population those having less awareness about the disease and to those have less income for life style modification the risk for DM increase. So this like studies should be performed in those in high risk population to know the prevalence of the disease and its risk factors.

\section{Limitations of the Study}

Lack of budget allocation that might be a big challenge to bought a glucose measuring device that is used to determine impaired fasting glucose or impaired glucose tolerance to the prevalence of DM and its risk score. Time constraint and small sample size are also the concern of this study. The CANRISK tool used for this study has not included many variables that can measure the risk for developing diabetes.

\section{Consent for Publication}

Not applicable

\section{Availability of Data and Material}

The data are available in the public library of Addis Ababa University in the form of soft and hard copy undergraduate's student directs the study.

\section{Competing Interests}

The authors declare that they have no competing interests.

\section{Funding}

The authors have declared that they received no financial support for their research.

\section{Authors' Contributions}

ZNW: Contributed in the design, data collection, and data entry and also made the data analysis, interpretation of the data and write up of the manuscript. ABB: also contributed to the data analysis, interpretation of the data, made an intellectual review of the paper and read and approved the final manuscript.

\section{Acknowledgements}

We acknowledge all health care professional staff and administrative bodies of TASH for their great cooperation for the success of the study. Authors are also grateful to the Ethiopian Diabetes Association for the support in providing the relevant research material for this study.

\section{References}

1. Ozougwu JC, Obimba KC, Belonwu CD, Unakalamba CB (2013) The pathogenesis and pathophysiology of type 1 and type 2 diabetes mellitus. J Physiol Pathophysiol 4: 46-57.

2. Rydén L, Standl E, Bartnik M, Van den Berghe G, Betteridge J, et al. (2007) Guidelines on diabetes, pre-diabetes, and cardiovascular diseases. Eur Heart J 28: 88-136.
3. International Diabetes Federation (2013) IDF DIABETES ATLAS. (6thedn) IDF.

4. WHO: The World Health Report (2002) Reducing Risks, Promoting Healthy Life. In. Geneva: World Health Organization.

5. Srinivasan BT, Davies MJ, Webb D (2007) Baseline characteristics and risk of progression from pre-diabetes to Type 2 diabetes in a multi-ethnic population based screening. Diabetic Medicine 24: 73.

6. International Diabetes Federation: Briefing on Diabetes Post 2015.

7. Abdulkadir J, Ahmed R (2001) Management of diabetes mellitus: coping with limited facilities. Ethiopian Medical Journal 39: 349-365.

8. Thoopputra T, Newby D, Schneider J, Li SC (2012) Survey of diabetes risk assessment tools: concepts, structure and performance. Diabetes Metab Res Rev 28: 485-498.

9. Hydrie MZI (2012) Risk factors for Type 2 Diabetes Mellitus: Metabolic Syndrome, Insulin Resistance and Primary Prevention. Doctoral Thesis University of Oslo 2012.

10. Wichai A, Pongamorn B, Mark W, Piyamitr S, Sayan C, et al. (2006) A Risk Score for Predicting Incident Diabetes in the Thai Population. Diabetes Care 29:1872-1877.

11. Khan M (2011) Lifestyle Modification in the Prevention of Type II Diabetes Mellitus. Oman Med J 27: 170-171.

12. Houston TK, Person SD, Pletcher MJ, Liu K, Iribarren C, et al. (2006) Active and passive smoking and development of glucose intolerance among young adults in a Prospective cohort: CARDIA study. BMJ 332: 1064-1069.

13. Latchan Z, Seereeram R, Kamalodeen A, S Sanchez, Deonarine U, et al. (2010) TRAQ-D (Trinidad Risk Assessment Questionnaire for Type 2 Diabetes Mellitus): a cheap, reliable, non-invasive screening tool for diabetes. The British Journal of Diabetes and Vascular Disease 10: 187-192.

14. Gray LJ, Tringham JR, Davies MJ, Webb DR, Jarvis J, et al. (2010) screening for type 2 diabetes in a multiethnic setting using known risk factors to identify those at high risk: a cross-sectional study. Vascular Health and Risk Management 6: 837-842.

15. Alberti KG, Zimmet P, Shaw J (2017) International Diabetes Federation: a consensus on Type 2 diabetes prevention. Diabetic Medicine 24: 451-463.

16. Public Health Agency of Canada: CANRISK: the Canadian diabetes risk questionnaire user guide for pharmacists.

17. Otero LM, Fong M, Papineau D, Thorne S, Zanetti ML (2011) Testing a prediabetes screening approach for a Latin American population in Vancouver, Canada. Nursing Healthcare Chronic Illness 3:329-338.

18. Acemoglu H, Ceylan A, Saka G, Plalanci Y, Erten M, et al. (2001) Risk factors for diabetes in South Eastern Anatolia of Turkey. Int J Epidemiol 3: $1540-2614$.

19. Al Khalaf MM, Eid MM, Najjar HA, Alhajry KM, Doi SA, et al. (2010) Screening for diabetes in Kuwait and evaluation of risk scores. Eastern Mediterranean Health Journal 16: 725-731.

20. Megerssa YC, Gebre MW, Birru SK, Goshu AR, Tesfaye DY (2013) Prevalence of Undiagnosed Diabetes Mellitus and its Risk Factors in Selected Institutions at Bishoftu Town, East Shoa, Ethiopia. Diab Metab S12: 008.

21. On'Kin K, Longo-Mbenza B, Okwe N, Kabangu NK, Mpandamadi SD (2008) Prevalence and risk factors of diabetes mellitus in Kinshasa Hinterland. Int J Diab Metab 16:97-106.

22. Ahmad J, Masoodi MA, Ashraf M, Rashid R, Ahmad R, et al. (2011) Prevalence of Diabetes Mellitus and Its Associated Risk Factors in Age Group of 20 Years and Above in Kashmir, India. Al Ameen J Med Sci 4: 1.

23. Azimi-Nezhad M1, Ghayour-Mobarhan M, Parizadeh MR, Safarian M, Esmaeili H, et al. (2008) Prevalence of type 2 diabetes mellitus in Iran and its relationship with gender, urbanisation, education, marital status and occupation. Singapore Med J 49: 571-576.

24. Omolafe A, Mouttapa M, McMahan S, Tanjasri SP (2010) We are family: Family History of Diabetes among African Americans and its Association to Perceived Severity, Knowledge of Risk Factors, and Physical Activity Levels. Californian J Health Promo 8: 88-97. 
Citation: Wakjira ZN, Berha AB (2017) Screening Employees for Undiagnosed Type 2 Diabetes Mellitus and Evaluation of Risk Scores in Tikur Anbessa Specialized Hospital, Addis Ababa, Ethiopia. J Diabetes Metab 8: 765. doi:10.4172/2155-6156.1000765

Page 10 of 10

25. Nyenwe EA, Odia OJ, Ihekwaba AE, Ojule A, Babatunde S (2003) Type 2 diabetes in adult Nigerians: a study of its prevalence and risk factors in Port Harcourt, Nigeria. Diab Res Clin Practice 62: 177-185.

26. Mutebi E, Nakwagala F, Nambuya A, Otim M (2012) Undiagnosed diabetes mellitus and impaired glucose tolerance among hypertensive patients in Mulago hospital, Kampala, Uganda. Afr J Diab Med 20: 20-23.

27. Balakrishnan V, Sreedharan J, Muttappallymyalil J, Valliyot SB (2013) Risk Factors of Type 2 Diabetes Mellitus in the Rural Population of North Kerala, India: A Case Control Study. Diabetologia Croatica 42: 33-40.

28. Govindarajan G, Sowers JR, Stump CS (2006) Hypertension and Diabetes Mellitus. European Cardiovascular Disease 2006: 1-7.

29. Aekplakorn W, Bunnag P, Woodward M, Sritara P, Cheepudomwit S, et al. (2006) A risk score for predicting incident diabetes in the Thai population. Diabetes Care 29: 1872-1877.
30. Dong JJ, Lou NJ, Zhao JJ, Zhang ZW, Qiu L, et al. (2011) Evaluation of a risk factor scoring model in screening for undiagnosed diabetes in China population. Journal of Zhejiang University-SCIENCE B (Biomedicine \& Biotechnology) 12: 846-852.

31. Verma A, Boney CM, Tucker R, Vohr BR (2002) Insulin resistance syndrome in women with prior history of gestational diabetes mellitus. J Clin Endocrinol Metab 87: 3227-3235.

32. Kawakami N, Takatwuka N, Shimizu H, Ishibarshi H (1997) Effect of smoking on the incidence of NIDDM. Replication and extension in a Japanese cohort of male employee. Am J Epidemiol 145: 103-109.

33. Hur NW, Kim HC, Nam CM, Jee SH, Lee HC, et al. (2007) Smoking cessation and risk of type 2 diabetes mellitus. Korea Medical Insurance Corporation Study 14: 244-249. 